\title{
Assessment of Healthcare Waste Management Practices in Enugu Metropolis, Nigeria
}

\author{
Clementina Ukamaka Uwa
}

\begin{abstract}
This study was carried out with the aim of assessing the health care waste management practices by hospital staff. The study involved the survey of a cross section of four (4) tertiary health institutions. The study showed that there is significant variation in healthcare waste management practices and the sustainability factors (reduce, reuse recycle)(3Rs). The test showed that there prominent method of healthcare waste management at the studied institutions was practice of incineration and frequency of waste disposal, leaving out other new and improved technologies for proper waste management. The study showed that the health institutions adopts minimal activities of recycling, reduce and reuse, although not regularly. It is therefore imperative that new technologies and innovations should be put in proper place for improved healthcare management practices, in Enugu metropolis. The aim of this research therefore is to assess the healthcare management practices using it tertiary health institutions (teaching and specialist hospital) in southern Nigeria, state of Enugu as a case study. This paper therefore sets out to assess the healthcare waste management practices of health workers in those health institutions.
\end{abstract}

Index Terms-Assessment, waste, management.

\section{INTRODUCTION}

Health care waste $(\mathrm{HCW})$ is a by-product of health care activities (HCAs). They comprise sharps such as syringes, needles and blades: non-sharps, such as swabs and bandages; blood and body parts; chemicals, such as mercury, solvents and disinfectants; pharmaceuticals and radioactive materials [1]. In addition, medical waste includes expired, unused, split and contaminated pharmaceutical products, drugs, vaccines, and sera that need to be disposed appropriately. It also includes discarded items contaminated from use in the handling of pharmaceuticals, such as bottles or boxes with residues, masks, connecting tubing, syringe bodies and drug vials (see Fig. 1 and Fig. 2).

Health care waste management (HCWM) inadequacies are increasingly compounding adverse environment and public health conditions in many developing world cities. In industrialized countries, efforts at innovative and sustainable collection, treatment and disposal of $\mathrm{HCW}$ began in the early 1980s. The driver was the surge in the use of disposable equipment and materials which led to the production of unprecedented quantities of often hazardous waste [2]. Furthermore, the traditional methods of incineration employed in hospitals could not meet the

Manuscript received September 4, 2013; revised November 8, 2013.

C. U. Uwa is with the Department of Basic Sciences, Institute of Management and Technology, Enugu Nigeria (e-mail: uwaamakamma@yahoo.com). standards of the new clean air legislation of US Environmental Protection Agency. The outcome was that the hospitals were forced to shutdown their operations.

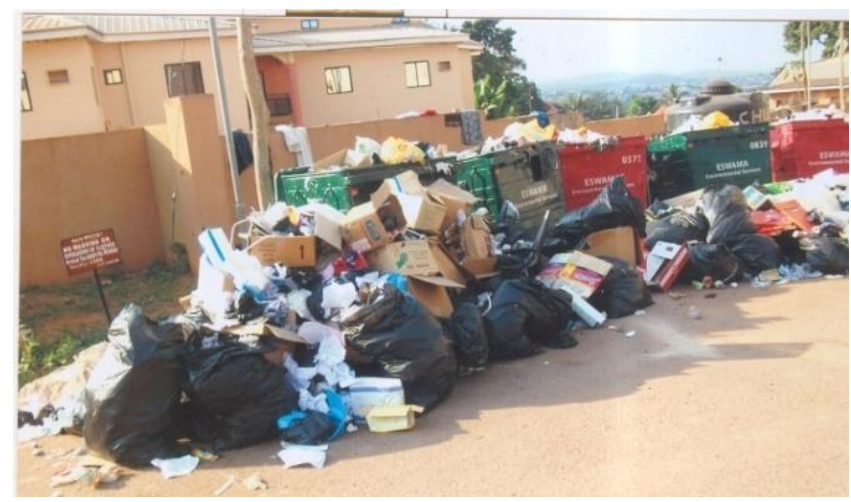

Fig. 1. Hospital waste dumped indiscriminately at a tertiary health facility.

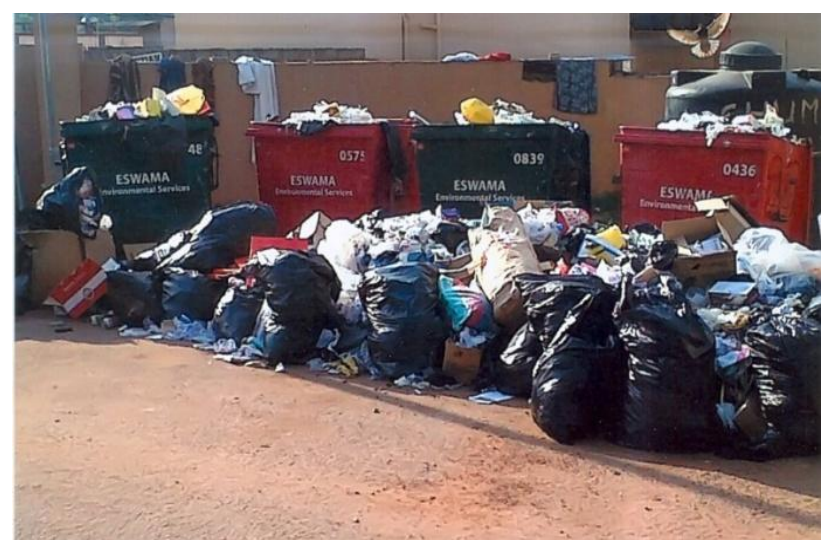

Fig. 2. Risk and non-risk health care waste mixed together in the waste containers.

\section{Health CARE Waste Management: TREatment AND MANAGEMENT}

The literature on healthcare waste management (HCWM) is rich in studies which explore and expound various management approaches and methodologies for the achievement of an effective, responsive and sustainable process. The crux of the matter, however, is the existence of discernible dichotomy in the profile of the highly complex HCW which consists of a waste treatment component and a management dimension both of which must of necessity be treated holistically. According to [3] the management dimension of HCWM comprise such issues as: legal framework and policy planning, organizing, human resources including training and capacity building, finance; institutional arrangement and monitoring for efficacy and effectiveness.

On the other hand, the treatment of HCW is dominated by 
technology concerns comprising incineration, safe landfill; sterilization; autoclaves and microwaves, chemical disinfection; and design of HCW transportation. According to [4], these technology aspects focus on safe, efficient and sustainable methods of handling, treatment and disposal of wastes from healthcare activities. The elements comprise segregation, packaging and treatment for reduction in volume, transporting, processing of hazardous and nonhazardous waste and disposal.

A number of studies demonstrate, however, that both treatment and management dimensions of HCM need to be examined holistically. It is this view which informs the espousal of the holistic approach to management of HCW as an essential component for preventive health system. In support of this view, [5] posit that management of HCW is not strictly about data compilation and technology of waste treatment and disposal but also involves training, commitment, management, leadership and effective legislative.

As rightly pointed out, treatment and management of HCW for sustainability need to incorporate all the elements of both management and technical. These elements are listed as planning and procurement, staff training and behaviour, proper use of tools, machines and pharmaceuticals, proper methods applied to segregation, reduction in volume, treatment and disposal[6].

\section{A. Major Issues in HCW Treatment and Management}

\section{1) $\mathrm{HCW}$ treatment}

The treatment dimension of HCW has equally generated a great number of studies. The reason is that the nature of the components of HCWs, their toxicity and potential hazard are different, necessitating different methods and options for treatment and disposal [7]. Different methods have been developed for rendering biochemical waste environmentally innocuous and aesthetically acceptable [7]. Other methods of treatment have been developed [7]. However, different studies have shown that there is no single method of medical waste treatment or disposal that completely eliminates all risks to humans or the environment.

\section{2) Incineration of $\mathrm{HCW}$}

Of the technologies to be considered in the management of $\mathrm{HCW}$, incineration of which there are many types, are a prominent medium [8]. Consequently, all aspects of incineration of $\mathrm{HCW}$ are an approach that has received a great deal of attention in HCW literature. They include the question of identification of environmentally sound technologies construction and documentation [9] and types of incinerators which include autoclave [10] and a new innovation known as hydro clave treatment; [11] and microwave and chemical disinfection. [12] made a strong case in favour of management dimension of HCWM. According to him technology can help but has to be part of a larger solution. Instead, emphasis should be on training for segregation, local house, keeping and disinfection, safety practices for nurses, ward boys and rag pickers from occupational hazard view point, and waste minimization which can help ultimately to solve the problem of medical waste.

With due attention to alternative for the treatment of and disposal of healthcare waste, [13] examined the question of non-incineration of medical waste treatment technologies in Europe which is of interest to developing countries; while [14] focused on small-scale medical waste incineration. With regard to the use of technology in HCWM, [15] rightly argued that the approach can be seen as a major limitation to introducing safe HCWM systems. He expounded further that developing counties often do not have support systems to install, maintain and operate developed world environmental technologies. The sustainable approach, he stressed, is to accommodate the use of more environmentally sound technologies (ESTs) in the design of HCWM system. [16] argued in favour of incineration of general infectious waste as long as pharmaceutical waste is not more than $1 \%$ of the total to limit toxic emissions into the air.

\section{3) Sharps}

(i.e. syringes) management in HCW has a high profile because of the enormous adverse health impact and risk worldwide. For example, the estimates that unsafe injections cause approximately 30,000 new HIV infections, 8 million HBV infections, and 12 million HCV infections worldwide every year. The WHO/USAID also examined two alternative approaches. One is a cost effective and waste management perspective in which syringes can be re-used (after proper cleaning and sterilisation in a steam sterilizer) in preference to disposable syringes; the other is a public health perspective involving one time use of auto-destruct needles. An appropriate summary proposed by [17] is to base the choice of disposal facilities on the type of treatment and the choice of treatment to determine the choice of disposal facilities.

\section{4) HCW segregation}

Waste segregation is a critical first step for the achievement of waste minimization, cost reduction and sustainable waste management [18] and offers the health facility the means to make more accurate assessment of their waste composition and also positions the facility for practical HCWM strategies. The emphasis in HCW is segregation of source. The [19], [20] recommends the segregation of HCW preferably at the source of production and provides guidelines for the safe and sound management of medical waste in developing countries. The use of instructive posters and colour coded bins are important to achieve effective segregation of waste. [21] in their study of infectious waste in Saudi Arabia hospital have also reported the importance of providing instructive posters as tool to promote effective segregation of HCW. The WHO, 2006 in their study, noted that the lack of HCW management manual and hospital policy on HCW management are likely to be responsible for the low awareness of health workers on HCWM. This is consistent with the outcome from other studies [22]. The guiding principle recommended is the minimization of non-hazardous HCW impacts in terms of quantity or ill-effects by reducing quantity of wastes, reusing the waste products with simple treatments and recycling the wastes by using it as resources to produce same or modified products - an approach referred to as $3 \mathrm{R}$ which stands for reduce, reuse, recycle. The 3 Rs was given a high priority at the 2002 World Summit for Sustainable Development (WSSD). 


\section{5) Management}

The management component of HCW depends on good governance as one of the main strategic factors that need consideration for the success of raising the standard of HCW management in HCFs. The others are institutional arrangements which include framing of appropriate HCWM policies, laws, regulations, guidelines, standards and enabling instruments. Other factors suggested includes clear cut roles and responsibilities, capacity building through knowledge sharing, enabling policy framework addressing economic and market-based instruments, facilitation or providing accurate and timely information to all stakeholders and financing which is considered a fundamental issue.

The objective is to assess Healthcare Waste Management (HCWM) practices currently employed at HCFs in Enugu Metropolis.

\section{ThE STUDY AREA}

Enugu metropolis is in the capital of Enugu State of Nigeria. The study area is Enugu Metropolis comprising Enugu City and the wider Enugu Metropolis within which is located the HCFs of interest namely: the University of Nigeria Teaching Hospital (UNTH) located formerly near the Prisons but now located at the new permanent site at Ituku Ozalla; Enugu State University of Science and Technology (ESUTH) Teaching Hospital, located in the GRA; the National Orthopaedic Hospital Enugu (NOHE) located at Nike; and Niger Foundation Hospital and Diagnostic Centre on Presidential close in the Independence Layout, Enugu city covers an area of $113 \mathrm{~km} 2$ while Enugu Metropolis cover an area of $200 \mathrm{~km} 2$ and by implication the UNTH at Ituku Ozalla falls within the Metropolis (see Fig. 3).

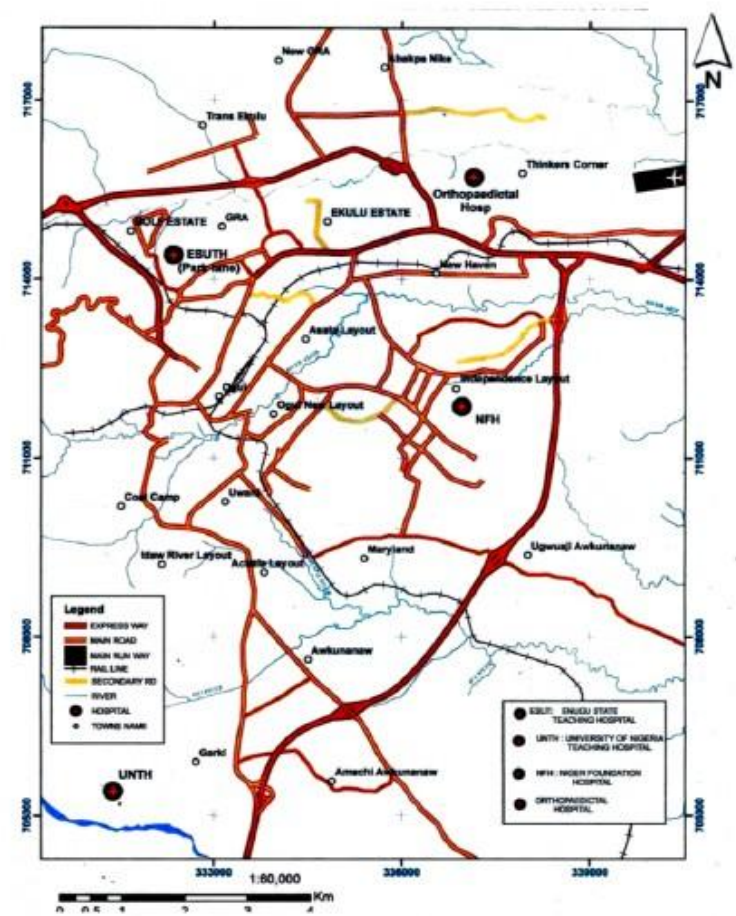

Fig. 3. Map of Enugu metropolitan area showing the city LGA \& tertiary HCFs.

Enugu is the capital of Enugu State. It is located in the
South Eastern area of Nigeria. The city has a population of 722,664 according to the 2006 Nigerian census (Federal Republic of Nigeria official Gazette, 15 May, 2007, Legal Notice on publication of the Details of the breakdown of the National and State Provisional Totals of 2006 Census).

The city is located within latitude 6o23', 7o30' North, longitude 7o30', and 8o19 East of the Greenwich Meridian. It lies between 200 and 300 meters above sea level, having an area of about $79.2 \mathrm{sq} . \mathrm{km}$. The city lies mainly on Asata Nkporo Shale sedimentary formation and on the northeast out-crop of the basal section of the lower coal measures (see Fig. 4).

The vegetation is generally loosing its original forest to savannah type. Thick green belt's running down along riverine and rivulets that criss-cross the city has insured that the city scape is entirely metropolitan.

The city has a moderately undulating terrain with slopes ranging between $1 \%$ and $25 \%$, thus enhancing effective drainage as runoffs easily empty into the network of natural drainage channels criss-crossing the city. It is, however important to note that relative to the position of the dominant escarpment, Enugu is a depression. This has made the city relatively susceptible to air/water pollution.

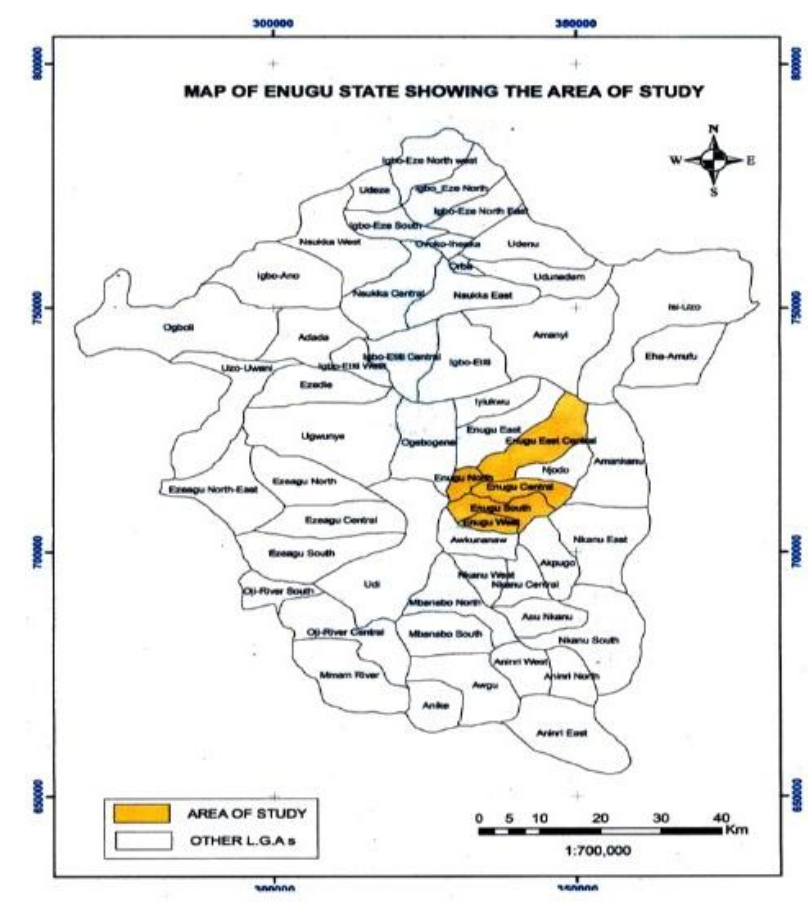

Fig. 4. Map of Enugu State showing the area of study.

\section{MATERIAL AND METHODS}

This study was carried out between November 2008 and December, 2012 as a cross sectional descriptive and inferential study at four (4) tertiary healthcare institutions in Nigeria based on the principal compact analysis.

Using the lists obtained from the personnel departments of the hospitals, a total of 2577 healthcare staff was obtained. Using the [23] analysis formula, a population of 400 was deduced approximately. A total of 400 questionnaires were randomly administered to healthcare staff, comprising of 9 administrators, 304 Doctors / Nurses and 87 orderlies / waste handlers. The questionnaires were administered by researchers and it consists of questions of 
their knowledge and practice of health care waste management, knowledge and practice of waste handling, Segregation, color coding, waste treatment and waste management. For proper assessment on healthcare waste management of the hospitals, the key researchers were able to interview the various heads of Departments of the hospitals administration face to face and also using telephone oral methods to obtain accurate information on the management of the healthcare waste. The main questions asked were:

1) The various healthcare management practices observed.

2) Personnel allotted to each ward.

3) Training of waste handlers.

The waste management practices of the hospitals was assessed using checklist of [24] Standards.

\section{RESULTS}

The null hypothesis attempts to compare the differences that exist in sustainability to reduce, recycle, reuse and other healthcare waste management practices. The principal component analysis and ANOVA (Analysis of Variance) was used to determine the difference between the current healthcare waste management practices in the four tertiary hospitals and the sustainability factors (3Rs).

Four (4) major sets of variables were employed to get component I that served as the dependent variable for the ANOVA.

$X_{1}=$ Frequency of sorting or segregation at source

$X_{2}=$ frequency of waste disposal per week

$X_{3}=$ Frequency of incineration of hazardous material to avoid direct emission

$X_{4}=$ Frequency of practice of recycling, reduce, and reuse of non-hazardous materials.

The collected data was subjected to the principal component analysis computation. The four variables were reduced to 2 components and then to 1 major components. The two (2) components with their variables loading (that is, the correlations, between each variable and the component, their eigen values (that is the sum of the squared loadings), the percentage of total explained variance, the cumulative percentage explained by each component plus the communalities (that is the proportion of the variance for each variable) explained by all the 2 components are presented in the Table I.

From the Table I, the rotated components which have 2 significant components together explained $62.015 \%$ of total variance, leaving $37.985 \%$ unexplained. The unexplained may be attributed to other factors that are not included in the analysis.

These two (2) components were further reduced to 1 single component. See Table II.

The component I has an eigen value of 1.437 and accounts for $35.917 \%$ of the total explained variance while component 2 has an eigen value of 1.044 and accounts for 26.098 of the total explained variance. This rotated component matrix was subjected to further analysis to extract one component. (See Table II) the highest loaded variable was $X_{3}=$ frequency of incineration of hazardous material to avoid direct emission (.798). This variable was used for one way Analysis of variance.
Table III gave the ANOVA computation summaries in respect of healthcare waste management practices and sustainability factors. In Table III with a calculated F-ratio of 6.946 which is greater than the critical values of 2.6049 at 0.05 probability level with degrees of freedom of 5 for the numerator and 256 for the denominator, the null hypothesis is rejected. We therefore conclude that there are significant variations in healthcare waste management practices and the sustainability factors (3Rs).

TABLE I: RotATED COMPONENT MATRIX OF HEALTHCARE MANAGEMENT PRACTICES

\begin{tabular}{|c|c|c|c|c|}
\hline \multicolumn{2}{|r|}{ Variables } & \multirow{2}{*}{$\begin{array}{l}\vec{\Xi} \\
\bar{\Xi} \\
\text { 泀 } \\
.638\end{array}$} & \multirow{2}{*}{$\begin{array}{l}\text { N } \\
\vec{\Xi} \\
\stackrel{\Xi}{\Xi} \\
\stackrel{\Xi}{\Xi} \\
-.272\end{array}$} & \multirow{2}{*}{ 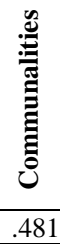 } \\
\hline$X_{1}$ & frequency of sorting/ segregation & & & \\
\hline$X_{2}$ & $\begin{array}{l}\text { frequency of waste disposal per } \\
\text { week }\end{array}$ & .013 & .956 & .914 \\
\hline$X_{3}$ & $\begin{array}{l}\text { frequency of incineration of } \\
\text { hazardous material to avoid } \\
\text { direct emission }\end{array}$ & -.798 & .247 & .698 \\
\hline$X_{4}$ & $\begin{array}{l}\text { frequency of practice of } \\
\text { recycling, reduce and reuse of } \\
\text { non hazardous waste }\end{array}$ & -.623 & .006 & .388 \\
\hline \multicolumn{2}{|c|}{ Eigen values } & 1.437 & 1.044 & \\
\hline \multicolumn{2}{|c|}{ Percentage variance explained } & 35.917 & 26.098 & \\
\hline \multicolumn{2}{|c|}{ Cumulative percentage } & 35.917 & 62.015 & \\
\hline
\end{tabular}

Source: Statistical Computation (2012)

TABLE II: ROTATED COMPONENT MATRIX

\begin{tabular}{|c|c|c|}
\hline \multicolumn{2}{|r|}{ Variables } & Comp. 1 \\
\hline$X_{1}$ & Frequency of sorting or segregation at source & .638 \\
\hline$X_{2}$ & Frequency of waste disposal/week & .013 \\
\hline$X_{3}$ & $\begin{array}{l}\text { Frequency of incineration of hazardous material to } \\
\text { avoid direct emission }\end{array}$ & .798 \\
\hline$X_{4}$ & $\begin{array}{c}\text { Frequency of practice of recycling, reduce, and reuse } \\
\text { of non-hazardous waste }\end{array}$ & 623 \\
\hline
\end{tabular}

Source: Statistical Computation (2012)

TABLE III: SUMMARY OF ANALYSIS OF VARIANCE TEST FOR COMPARING MEAN VALUES OF WASTE MANAGEMENT PRACTICES AND THE SUSTAINABILITY FACTORS

\begin{tabular}{|c|c|c|c|}
\hline $\begin{array}{c}\text { Source of } \\
\text { variation }\end{array}$ & Between groups & Within groups & Total \\
\hline$d f$ & $(k-1) 6-1=5$ & $\begin{array}{c}N-k=257-6= \\
251\end{array}$ & $\begin{array}{c}N-1= \\
257-1= \\
256\end{array}$ \\
\hline $\begin{array}{l}\text { Sum of } \\
\text { squares }\end{array}$ & $S S_{B}=90.415$ & $S S_{W}=653.406$ & 743.821 \\
\hline $\begin{array}{c}\text { Mean } \\
\text { squares }\end{array}$ & $\frac{S S_{B}}{d f}=18.083$ & $\frac{S S_{W}}{d f}=2.603$ & \\
\hline$F$-cal & $\frac{M S_{B}}{M S_{W}} F=6.946$ & & \\
\hline $\begin{array}{c}\text { Critical } \\
\text { value of } F\end{array}$ & $\begin{array}{c}\text { At } 0.05 \text { critical value }= \\
2.6049\end{array}$ & & \\
\hline Significance & $S$ & & \\
\hline Decision & Reject $H_{\mathrm{o}}$ & & \\
\hline
\end{tabular}

Source: Statistical Computation (2012)

$S-$ significant

\section{SUMMARY OF FINDINGS AND DISCUSSION}

\section{A. Summary of Findings}

After the analysis, the testing of the hypothesis shows that the null hypothesis is rejected and the alternative hypothesis is accepted. This shows that there is significant difference 
between healthcare waste management practices and the sustainability factors. The principal component analysis (and the analysis of variance (ANOVA) test performed to find out whether the practices in healthcare waste management are sustainable proved different.

\section{B. Discussion}

The findings in respect of the hypothesis showed that incineration and disposal are the prominent method of healthcare waste management in studied health facilities. These two constitutes a sizeable percentage of $62.015 \%$ of the total healthcare waste management practices at the health facilities. The level of waste minimization at tertiary health facilities in Enugu is extremely poor or does not exist at all. Even though the HCFs adopt minimal recycling, reuse or reduction, this is not done on a very regular basis. Furthermore, this cannot be done effectively as the level of sorting/segregation of waste is very poor. Wastes are hardly treated, are not properly handled by assigning proper colour codes and the use of separate bins for sharps and non-sharps for final wastes disposal and the disposals from the hospitals to landfills are not frequently performed. This findings does not agree with the study done by [25] on issues in technology innovation. The findings on lack of proper healthcare management practices may be due to lack of current technologies being employed at the various hospitals. Recently, mobile technology has been introduced to help with chronic disease management, empowering the elderly and expectant mothers.

\section{CONCLUSION}

The healthcare waste management practice is actually significantly different from the sustainability factors (3Rs). The null hypothesis was rejected after using PCA and ANOVA for the test. The test showed that the prominent method of healthcare waste management at the studied facilities were practice of incineration and frequency of waste disposal; leaving out other new and improved technologies for proper waste management. The study showed that the health facilities adopts minimal activities of recycling, reduce and reuse, although not regularly. It is therefore imperative that new technologies and innovation should be put in proper place for improved healthcare waste management practices.

\section{REFERENCES}

[1] WHO, Western Pacific Region, Workshop on Healthcare Waste Management Planning. Planning and Implementation, Meeting Report, Ulaanbaatar, Mongolia, 2008.

[2] Federal Environmental Protection Agency (FEPA), National Interim Guidelines and Standards for Industrial Effluents, Gaseous Emissions and Hazardous Waste Management in Nigeria, FEPA, Abuja, 1991,

[3] WHO/USAID Vital to Health? Briefing Document for Senior Decision-making (Draft), 1998

[4] WHO, "Safe management of waste from healthcare activities," World Health Organisation, Geneva, 1999.

[5] G. V. Patil and A. V. Skedhar, "Health-care waste management in India," Journal of Environmental Management, vol. 63, pp. 211-220, 2001.

[6] R. C. Sah. (July 2007). Bio-Medical waste management practice and POPs in Kathmandu, Nepal. Centre for Public Health and Environmental Development of Kathmandu, Nepal. [Online] Available: http://www.noharm.org/ details.cfm
[7] Research Triangle Institute, Review and Evaluation of Existing Literature on Generation, Management and Potential Health Effects of Medical Waste, Health Assessment Section, Technical Assessment Branch, Office of Solid Waste, U. S. Environmental Protection Agency, November 1988.

[8] S. Barb and M. Condon, "The problems posed by medical waste," Incineration Health Care without Harm, 1999.

[9] T. S. M. Ramabitsa-Simane, "The identification of environmentally sound technologies for healthcare waste management in Lesotho," Master thesis, Department of Engineering and Technology Management, University of Pretoria, 2006.

[10] D. Picken, "De montfort mark 8a incinerator construction documentation," De Montfort University, U. K., PAHO 2008 Public Health of Ordinance Cap 164 of 1959, June 2008,.

[11] M. Kela, S. Nazareth, A. Goel, and R. Agarwal, Managing Hospitals Waste: A Guide for Healthcare Facilities, Shristi, New Delhi, 1999.

[12] J. Emmanuel, C. Hodkinka, P. Gluzynski, R. Ryder, A. Mckeen, M. Berkemaier, and R. Gauthoier, "Non-Incineration medical waste treatment technologies in Europe," Healthcare without Harm Europe, Czech Republic, 2004

[13] D. E. C. Rogers, A. C. Brent, and B. Rohwer, "Life Cycle check as decision support tool for medical waste management in underdeveloped areas of Africa," in Proc. International Waste Management Biennial Congress \& Exhibition, Durban, South Africa, 2002, vol. 1, pp. 122-123.

[14] A. C. Brent, D. E. C. Rogers, T. S. M. Ramabitsa-Siimane, and M. B Rohwer, "Application of the analytical hierarchy process to establish healthcare management systems that minimise infection risks in developing countries," European Journals of Operational Research, vol. 181, pp. 403-424, 2007.

[15] A. Pruss, P. Grout, and P. Rushbrook, Safe Management of Waste from Healthcare Activities, World Health Organization, Geneva, 1999.

[16] A. K. Nema and S. K. Gupta, "Optimization of regional hazardous waste management systems: An improved formulation," Waste Manage, vol. 19, no. 7-8, pp. 441-451, 1999.

[17] H. Shaner, "An ounce of prevention: Waste reduction strategies of healthcare facilities," American Society for Healthcare Environmental Services, Chicago II, 1993.

[18] G. Going. (February 9, 2012). A resource bit for pollution prevention in healthcare. Healthcare without Harm. [Online]. Available: http://www.noharm.org

[19] World Health Organization (WHO), "Managing medical waste in developing countries," WHO, Geneva. 1994

[20] D. L. Hagen, A. Marthin et al., "Infectious waste surveys in a Saudi Arabian hospital. An important quality improvement tool," Am. J. Infect. Control, vol. 29, pp. 198-202, 2001.

[21] M. Askarian, M. Vakili, and G. Kabir, "Results from a hospital waste survey in private hospitals in Fars province, Iran," J. Waste Manag. vol. 24, pp. 347-352, 2004.

[22] K. Shimuzu, "Environmental Management: 3R (Reduce, Reuse, Recycle) Sustainable Production and Consumption (SPC) Training Course material," presented at 34th International Training Course on Regional Development in Japan, 18May-28 June, 2006, Nagoya: United Nations Centre for Regional Development (UNCRD), 2006.

[23] T. Yamani, An Introductory Statistical Analysis, Harper and Publisher, New York, 1967.

[24] WHO, "First do no harm: Introducing auto-disable syringes and ensuring injection safety in immunization systems in developing countries," Expanded Programme on Immunization and the Department of the Protection of Human Environment: WHO/V \& B/02.26, 2002

[25] W. Darrell, "How mobile devices are transforming healthcare," Issues in Technology Innovation, May 2012.

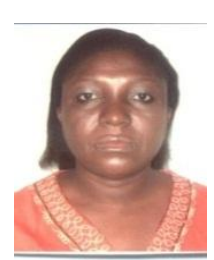

C. U. Uwa was born in Anambra State on June 13, 1965. She got her first degree (B.Sc.) on zoology in 1987 from the University of Jos, and the second degree on environmental resources management from Imo State University and Ph.D. in environmental management and pollution from University of Nigeria, Nsukka. She is currently working with Institute of Management and Technology, Enugu. She has authored many books like General Biology, (An Advanced Approach) ISBN 988-37125-9-2. Fundamentals of General Biology and many Journals. Dr.Uwa is a member of Environmental Society of Nigeria and Science Teachers Association of Nigeria. 